\title{
INFORMATION PROCESSING AS A DETERMINANT OF EFFECTIVE MANAGEMENT
}

\author{
Łukasz RYBAK ${ }^{1 *}$, Janusz DUDCZYK ${ }^{2}$, Zdzisław JEZIERSKI ${ }^{3}$ \\ ${ }^{1}$ Institute of Computer Science and Technology, Stefan Batory State University; 1rybak@pusb.pl \\ ${ }^{2}$ Institute of Computer Science and Technology, Stefan Batory State University; jdudczyk@pusb.pl \\ ${ }^{3}$ Institute of Security Sciences, Stefan Batory State University; zdzislawjezierski@wp.pl \\ * Correspondence author
}

Purpose: The aim of this article is to present the process of information processing as an element correlated with effective management. The authors have already quoted the information hierarchy in their own published papers a few times. This paper is a kind of systematization of knowledge concerning the process of information processing in terms of making strategic decisions and resources management.

Design/methodology/approach: In the paper the critical analysis of literature was carried out and the theoretical basis concerning the information hierarchy and the OODA loop was presented. The field of this paper concerns information processing in the context of management and decision supporting.

Findings: In each of the discussed literature references, the authors identified information hierarchy along with OODA loop. It allowed us to achieve the aim which was defined earlier, namely, to show information processing as an element correlated with effective management.

Research limitations/implications: In the paper a few examples were analysed. Therefore, the next step in the future research should be to focus at the review of a bigger amount of them. Originality/value: The paper shows that the information hierarchy could be used unconsciously in decision process. The authors showed how to detect the information hierarchy in a management process. The paper should be read by persons whose research interests are focused on the decision support by the information and communication technologies.

Keywords: information processing, management, information and communication technology, decision supporting, strategic thinking.

Category of the paper: Viewpoint, research paper.

\section{Introduction}

The increase in the number of processed information is strictly connected with the popularization of the Internet and creation of information society (Rybak et al., 2018). Research presented by Eurostat showed that in $2016,82 \%$ of EU citizens used the Internet, while $71 \%$ of 
respondents declared everyday use of the Internet (European Statistical Office, 2018). On the basis of the scale of this phenomenon, it can be stated that information processing in a digital form is one of the basic task for the ICT sector. In terms of cooperation, ICT systems are key tools to do everyday tasks in contemporary companies. It is hard to imagine a company which does not use ICT technology on the contemporary market. In the past, at the time when digitalization was not popularized, communication was much slower and electronic data storing and protection was impossible. Information was stored in a paper form and data updating was done manually. As a result it was much more difficult to exchange such information due to the fact that it was stored in one location only (Susanto et al., 2016). As presented in the research from 2014 to 2016, in the sector of small and medium-sized enterprises, the most computerized department in companies is finance and accounting, which was subject to computerization in as much as $82 \%$ of the examined enterprises (Adamczewski, 2016). In the context of management in a conflictual situation, C4I (command, control, communication, computers and intelligence) deserve to be highlighted as these are integral parts of the individual soldier combat system and support for the management process in network centric conditions, NCW. The C4I system derives from the C2 (command and control), which is a set of processes based on the use of information resources in order to achieve organisations and enterprises targets (Brehmer, 2005). C4I systems create effective and safe acquisition and analysis mechanisms, synthesis and data aggregation and sharing at every level of hierarchy. As a result, soldiers gain extra information and thus improve their knowledge. The C4I system integrates all radio, electronic and optoelectronic components as well as ICT elements, which are a part of soldier's equipment. An example of the C4I is Modular Integrator, which is described in (Dudczyk and Przanowski, 2017). In the aforementioned article, there is a detailed presentation of a design of this tool and its functionality. What needs to be emphasized it the fact that Modular Integrator for management of the C4I soldier system has received a number of prizes and honourable mentions. The article consists of an overview of our works connected with information processing decision making support (Rybak et al., 2018; Dudczyk and Rybak, 2018). This work is a kind of systematization of knowledge concerning the process of information processing in terms of making strategic decisions and managing own resources. The aim of this article is to present the information processing as an element correlated with effective management. In order to do it, in chapter 2 - Literature review, there is an overview of our two publications about information processing, in chapter 3 - The information hierarchy in the context of the strategical thinking, there is a detailed description of the process of information processing in correlation with the OODA cycle of strategic thinking. Finally, there is a presentation of results of our analyses i.e. information hierarchy and OODA loop in the described examples of management support systems. 


\section{Literature review}

\subsection{Visual information processing in epidemiology}

The first example of effective management as a result of information processing is the historical finding of the cause of a cholera epidemic in one of London districts in 1854, as well as stopping this infectious disease, which is described in (Rybak et al., 2018) with details concerning this fact presented in (Ball, 2009).

The whole study was carried out by John Snow, who used to live in Soho, near Broad Street. Viruses at that time were not tested (Rybak et al., 2018). Nevertheless, Snow talked to local residents and collected data concerning water consumption. Later on, he made a kind of data visualization, which resulted in a well-known map, which presented the location of deaths of London residents in a form of single black lines. In the centre of the tested area there was a public water pump on Broad Street (Ball, 2009), which can be noticed in the figure (Figure 1).

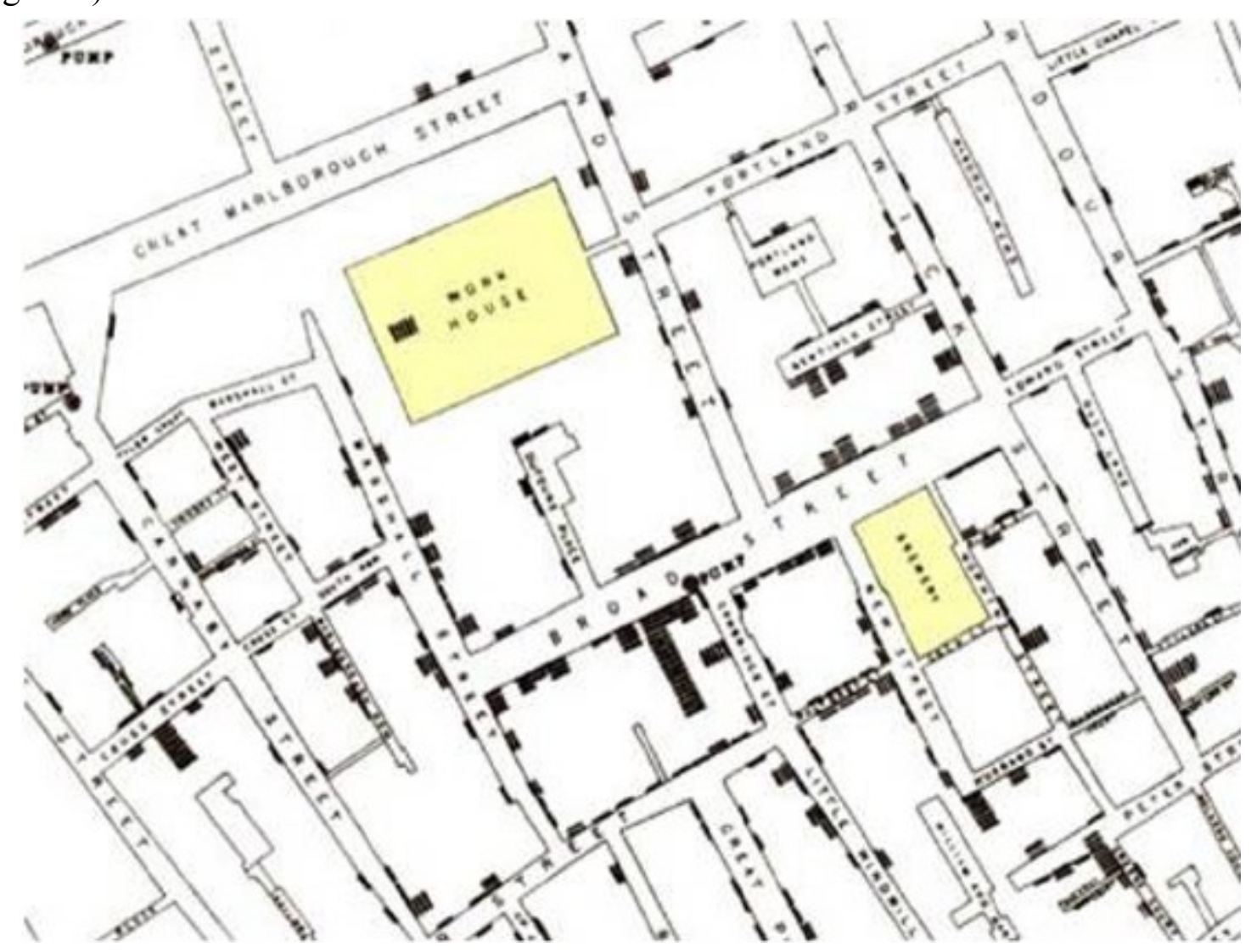

Figure 1. Fragment of the map developed by John Snow, source: (Gilbert, 1958).

On the basis of the received information as a result of the processing mentioned above, it might have been concluded that the outbreak of the disease had no explicit connection with the water pump on Broad Street as part of deaths were located much closer the other pumps. Taking into consideration lack of cohesion, Snow conducted several surveys among other local residents concerning the source of water on Broad Street. Therefore, by information exchange 
he created a source of knowledge, which eventually provided him with the conclusion that in Soho there was no cholera epidemic, and the deaths were only the effects of consuming water that came from the pump on Broad Street. The presented conclusion determined making a decision to disable the aforementioned well pump. In consequence, John Snow turned to particular authorities to obtain a specific permit and he managed to receive it, so the day after the pump was put out of commission.

The solution concerning the cholera epidemic was an innovation (Ball, 2009), which left John Snow's mark on contemporary epidemiological tests, which use for example geographical information systems, GIS (Rybak et al., 2018).

\subsection{Communication and information support of making decisions in a network-centric warfare}

Making a decision in conflictual situations requires forming particular, optimal strategies. Nowadays, broadly defined decision support is carried out with the use of Decision Support Systems (DSS). According to C4I, created systems are equipped with AI (Artificial Intelligence) algorithms. An example of a system influencing management effectiveness is the concept of Adaptive Decision Support System, which is described in detail in (Dudczyk and Rybak, 2018).

Network Centric Warfare (NCW) means an area in which there are organized connections between all subjects taking part in an operation and thanks to these connections such subjects have a possibility to share information. Creating safe and effective mechanisms of information processing and their later use in warfare conditions are the key elements that enable obtaining a network centric warfare (Dudczyk and Rybak, 2018).

Nowadays, there is a possibility to describe any fragment of the real world with the use of ordered data structures. The general ADSS idea is based on statistical analysis. At the beginning of this process it is necessary for a user to enter data, which is a numerical description of the situation on the warfare. This data must be normalized before the start of further processing in order to extract knowledge from it. As a result, a feature vector is generated. Then, it is transferred to a classifier, which uses k-nearest neighbours (k-NN) nonparametric regression algorithm. At this processing stage, each previous condition of a warfare, which is stored in a database, is considered as a single object in created feature space. K-NN classifier from a learning set - a set, where a specific state of warfare is connected with an optimal scenario of activities - chooses $\mathrm{k}$ of nearest objects. It needs to be emphasized that in statistical classification, the term the nearest does not explicitly refer to the distance, but to a certain, defined similarity measure. In the context of information hierarchy and OODA cycle at the classification stage, the process of orientation is carried out, during which some information about $\mathrm{k}$ of nearest objects appear. The next step is to make a decision on the basis of information about $\mathrm{k}$ of nearest scenarios of activities. As a result, knowledge about optimal operating algorithm is formed. A soldier in a network centric warfare needs to execute particular 
commands and observe, in the next OODA cycle, their effects and collect data describing a new condition of warfare area. In the aforementioned way adaptivity of the system is carried out. As a learning method, Instance-based Learning is used to define a target function every time a classifier receives a new sample. Such an action means breaking the canon of the rest of machine learning methods, which define the target function just at the moment of providing a learning set (Dudczyk and Rybak, 2018).

Efficient information processing and its effective use make it possible to gain advantage in network centric conditions (Dudczyk and Rybak, 2018). The concept above assumes that each soldier has a regular direct access to ADSS. In consequence, in a short time, a system user receives current image of the area where the action is taken. Moreover, the process of making decisions is supported in hard, dynamically changing warfare conditions.

\section{The information hierarchy in the context of the strategical thinking}

In each of the examples above it can be noticed that there are particular stages in the process of information processing. In order to consider information hierarchy in the context of the strategic thinking, it is necessary to discuss Boyd cycle, the so-called OODA loop (ObserveOrient-Decide-Act), which was used by John Boyd primarily to conduct military operations (Goncalves et al., 2009).

It needs to be emphasized that in contemporary business it is useful to implement a pattern of strategic thinking at particular management levels. That is why among business strategies adaptive strategical thinking (OODA) cycle gains more and more popularity (Goncalves et al., 2009).

A model of OODA adaptive loop for making decisions is a set of particularly ordered activities - to observe, orient, decide, act - which are conducted in a cyclical way (Rybak and Dudczyk, 2019):

Observation is a process of gathering (Rybak et al., 2018) and compilation of (Goncalves et al., 2009) data, which are often a numerical description of an area where the action is taken. From the business point of view these will include knowledge about strong and weak points of a particular organisation, data about orders, customer data and technological data (Goncalves et al., 2009). At this stage of OODA loop, feedback is significant i.e. a reaction on data, which is the result of the taken action in the previous iteration of OODA loop (Rybak et al., 2018).

Orientation is a stage in which there is an analysis of possible scenarios, which appear not only on the basis of observations, but also due to experience gained as a result of activities because these have a cyclical nature of the decision making model. The product of this stage are diagrams presenting a particular fragment of the real world. Their form determines the importance of potential activities. The idea of this stage is information exchange among 
members of the team. Such knowledge is usually too complicated to explain it to a third party due to being largely subjective (Goncalves et al., 2009).

Deciding is a stage in which specific, appropriate for a particular situation scenario is chosen on the basis of an image created at the orientation stage. It needs to be emphasized that this activity may be of conscious or involuntary character (Rybak and Dudczyk, 2019). Particular activities are performed at the next stage of OODA loop (Goncalves et al., 2009).

Acting is the last stage of OODA loop. Here, the scenario of the taken decision is carried out. It needs to be emphasized that activities carried out only once cause only a temporary adjustment of a company to the dynamically changing market. In a situation where a feedback provides results which are insufficient for company's demand, it is necessary to carry out next iteration of OODA loop, which might be helpful in identifying causes of failure and at the same time support the development of a more effective scenario.

One of many advantages of OODA loop is its adaptivity. Thus, it is effective in a dynamic environment with high complexity. Adaptivity is provided due to the transfer of up-to-date data of one cycle to next iteration - after this activity, further observation is carried out (Rybak and Dudczyk, 2019).

The increase of popularity of OODA loop in business sector results from growing competition and the necessity to develop new strategies enabling competition especially on less stable markets.

Discussing information processing as a determinant of effective management, what needs to be mentioned is the correlation of information hierarchy and OODA loop, described in the article (Rybak and Dudczyk, 2019), which was presented in the figure (Figure 2).

Further stages of information hierarchy correlated with OODA cycle can be looked into in a following way: data provide information, which gives knowledge and this leads to wisdom (Rybak and Dudczyk, 2019).

Data are usually numerical descriptions of a particular fragment of the real world, therefore, they are usually presented in a form of numbers (e.g. in machine learning such data will be values of particular features in a feature vector). It is also possible to present data in a form of texts (e.g. often labels of objects in machine learning). Data constitute the lowest level in information hierarchy. Objects, measures, events and observations presented in a numerical form are not a clear message for the receiver. To obtain relevant information, it is necessary to process the data.

Information is a product of inter alia acquisition, analysis, synthesis and data aggregation. Processed data receive a particular meaning. The information is presented in a form of elementary conclusions. As a result of this fact, the transfer of a message in a form of information is more clear in comparison with its exchange in a form of data, which can have an impact on its relevance. Information correlated with experience, awareness, and knowledge about particular facts determines gaining expertise. 


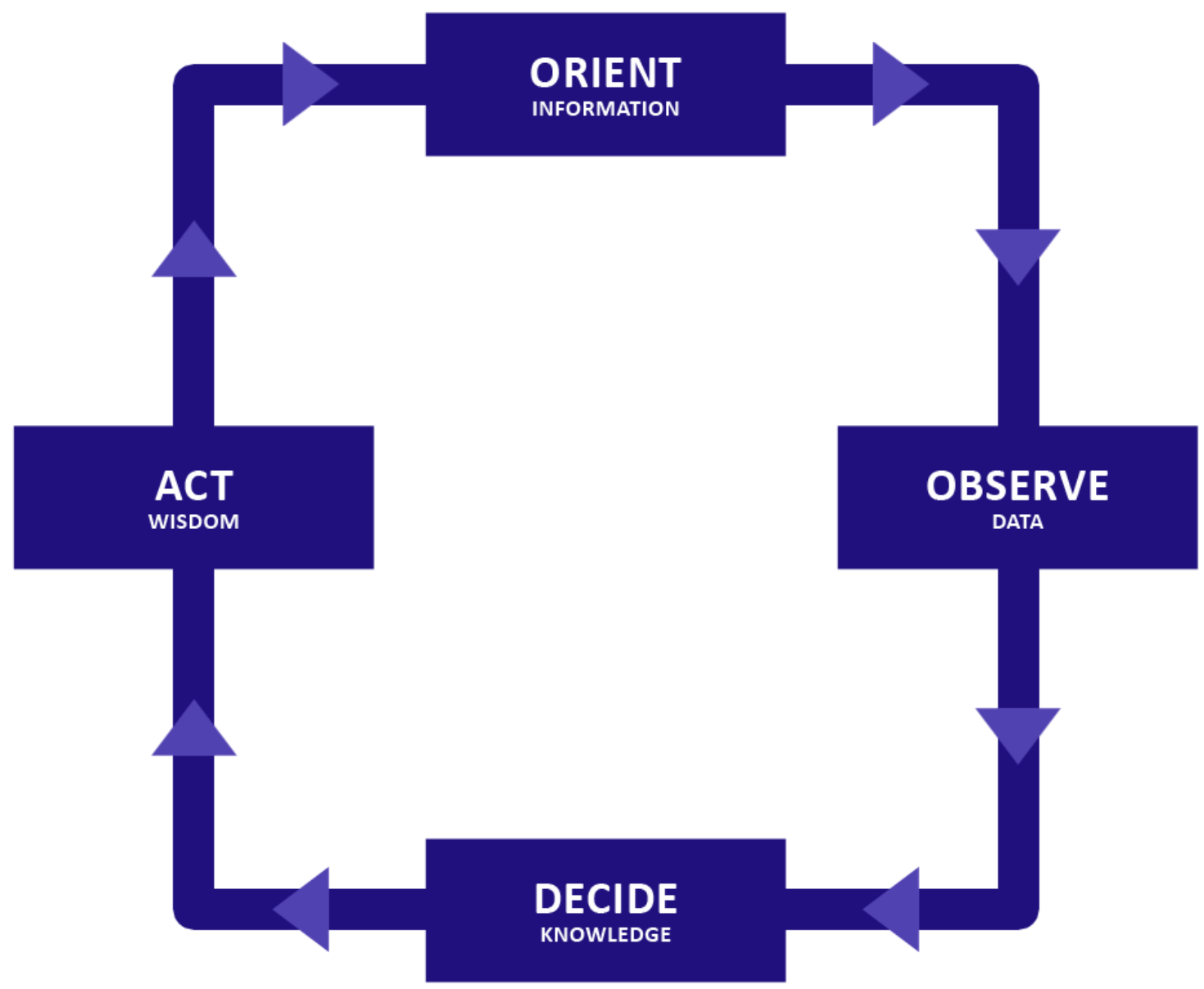

Figure 2. OODA loop correlated with information hierarchy, source: Own elaboration based on (Rybak and Dudczyk, 2019; Goncalves et al., 2009; Brehmer, 2005).

Knowledge are whole issues which the receiver learnt, concluded and observed. According to OODA loop, knowledge comes from information exchange at the orientation stage.

Wisdom is the last, highest level in information hierarchy. It can be perceived as a condition when a user has such an advanced level of knowledge that they have an ability to evaluate the data in precise way. It needs to be emphasized that so far in literature there have been no methods enabling learning or giving knowledge (Rybak et al., 2018).

Scientists also suggested modification of OODA loop. The modification presented in Brehmer's work certainly deserves to be mentioned (Brehmer, 2005). On the basis of the analysis of two dominant concepts of OODA loop in C2: the one suggested by Boyd between 1970 and 1980 and cybernetic approach, Brehmer suggested their hybrid variant eliminating most weak points of these concepts, but keeping their advantages. He called the suggested approach Dynamic Observe-Orient-Decide-Act, DOODA. The research presented in the article (Brehmer, 2005) showed that DOODA is a source of hypotheses concerning winning and losing, in comparison with OODA loop, which tends to be a model which is rather concentrated only on support of the process of making faster and faster decisions. 


\section{Results}

In the table below (Table 1) the results of a critical analysis were presented. The analysis was performed in the 3 criteria - information hierarchy levels, OODA loop stages and effectiveness. In this part the effectiveness should be understood in terms of the aims which were achieved. The results concern analysis of the two approaches and they were discussed in the next chapter of this paper (5. Conclusion).

\section{Table 1.}

The result of a critical analysis concerning identification of information hierarchy and OODA cycle in the presented examples of systems supporting decision making and management

\begin{tabular}{|c|c|c|c|}
\hline & Information hierarchy & OODA loop & Effectiveness \\
\hline 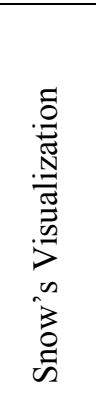 & $\begin{array}{l}\text { Data about the location of } \\
\text { each death. } \\
\text { Information about mutual } \\
\text { location of deaths and their } \\
\text { number in particular locations. } \\
\text { Knowledge concerning a } \\
\text { potential cause of each death. } \\
\text { Wisdom enabling to evaluate } \\
\text { particular deaths. }\end{array}$ & $\begin{array}{l}\text { Observe - data collection of each } \\
\text { death. } \\
\text { Orient - dealing with lack of } \\
\text { cohesion by interviews with the } \\
\text { residents. } \\
\text { Decide - making a decision about the } \\
\text { cause of deaths i.e. water coming } \\
\text { from the pump on Broad Street. } \\
\text { Act - closing the source of } \\
\text { contaminated water. }\end{array}$ & $\begin{array}{l}\text { Identification of the } \\
\text { cause of a cholera } \\
\text { epidemic in London } \\
\text { Soho district. }\end{array}$ \\
\hline 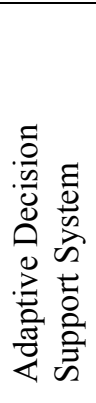 & $\begin{array}{l}\text { Data about the current warfare } \\
\text { conditions. } \\
\text { Information about the most } \\
\text { similar conditions from the } \\
\text { past. } \\
\text { Knowledge about an optimal } \\
\text { operating algorithm. } \\
\text { Wisdom enabling us to } \\
\text { evaluate realization of optimal } \\
\text { operating algorithm. }\end{array}$ & $\begin{array}{l}\text { Observe - data collection about } \\
\text { warfare conditions. } \\
\text { Orient - finding the most similar } \\
\text { conditions from the past. } \\
\text { Decide - choosing an optimal } \\
\text { operating algorithm in particular } \\
\text { conditions. } \\
\text { Act - a selected scenario of action is } \\
\text { conducted. }\end{array}$ & $\begin{array}{l}\text { Adaptivity resulting from } \\
\text { the idea of solution. } \\
\text { The increase in the pace } \\
\text { of commanding declared } \\
\text { by the authors. }\end{array}$ \\
\hline
\end{tabular}

Source: Own elaboration.

\section{Conclusion}

Examination of John Snow's visualization in the context of information hierarchy identification and Boyd's cycle requires an analysis when these appeared on the timeline. Snow's visualization was in 1854, whereas development of OODA happened between 1970 and 1980. Although between these events there is a 100-year gap and Snow acted before OODA loop, it is possible to notice and identify in his activities Boyd's cycle, which is correlated with information hierarchy. As part of orientation, Snow collected data about each death. The next step was to visualize information interrelationships between particular incidents - where and how many happened. By such information and consistent realization of orientation he exchanged information from the residents, As a result, he had knowledge about the cause of 
particular incidents. This determined making a decision about closing the public water pump on Broad Street. Finally, he realized this task.

ADSS consists of the data describing the current warfare conditions. As a result of a statistical analysis of particular objects, the system generates information concerning similarity between particular conditions of reality, indicating those most similar. On the basis of a training set ADSS generates an optimal for particular conditions scenario of activities and thus supports the soldier's decision, whose role is to do particular tasks. In further iteration, following data come as a response to activities realized in the previous iteration. Therefore, it is possible to notice information hierarchy correlated with OODA loop. In the context of effectiveness of this solution in the management process, adaptivity and increase in the command pace suggested by the authors are easily noticeable.

To sum up, on the basis of the conducted analyses for the purpose of this article, it can be stated that both of the described examples make it possible to carry out their aims in an effective way. Furthermore, in both cases information hierarchy and OODA loop are identified. Thus, it can be concluded that the aim of this research has been achieved - the process of information processing has been successfully presented as an element correlated with effective management.

\section{References}

1. Adamczewski, P. (2016). Z badań nad stanem informatyzacji polskiego sektora MSP w warunkach transformacji cyfrowej. Studia Informatica Pomerania, Vol. 4(42), pp. 5-14. DOI: $10.18276 /$ si.2016.42-01.

2. Ball, L. (2009). Cholera and the Pump on Broad Street: The Life and Legacy of John Snow. The History Teacher, Vol. 43(1), pp. 105-119.

3. Brehmer, B. (2005). The Dynamic OODA Loop: Amalgamating Boyd's OODA Loop and the Cybernetic Approach to Command and Control. 10th International Command and Control Research and Technology Symposium: The Future of C2. McLean, VA, USA.

4. Dudczyk, J., Przanowski, J. (2017). Application of the Modular Integrator for Soldier's C4I System Management on the Battlefield. Problems of Mechatronics. Armament, Aviation, Safety Engineering, Vol. 2(28), pp. 9-18. DOI: 10.5604/01.3001.0010.1567.

5. Dudczyk, J., Rybak, Ł. (2018). Adaptive Decision Support System in Network Centric Warfare Process. Elektronika (konstrukcje, technologie, zastosowanie), Vol. 7, pp. 39-42, ISSN: 0033-2089, DOI: 10.15199/13.2018.7.10.

6. European Statistical Office (2018). Digital economy and society statistics - households and individuals. Eurostat regional yearbook 2018, pp. 127-138, DOI: 10.2785/231975. 
7. Gilbert, E.W. (1958). Pioneer Maps of Health and Disease in England. The Geographical Journal, Vol. 124(2), pp. 172-183, DOI: 10.2307/1790244

8. Goncalves, A., Zacarias, M., Sousa, P. (2009). Alignment IT to business using OODA loop. Conference on ENTERprise Information Systems. Ofir, Portugal.

9. Rybak, Ł., Dudczyk, J. (2019). Increasing the information superiority on the modern battlefield through the use of virtual reality systems. Security and Defence Quarterly, 27 March, eISSN: 2544-994X.

10. Rybak, Ł., Dudczyk, J., Jezierski, Z. (2018). The IT sector as an important element of critical infrastructure. Infrastruktura krytyczna $w$ systemie bezpieczeństwa państwa i społeczeństwa. Oficyna Wydawnicza PWSZ w Nysie, pp. 123-134, ISBN: 978-83-6588105-2.

11. Susanto, H., Chin Kang, Ch., Leu, F. (2016). Revealing the role of ICT for business core redesign. Information Systems \& Economics eJournal. 